\title{
Possibilities of using social networks in the modern educational process in universities
}

\author{
V.A. Buzni ${ }^{1 *}$, M.E. Ivanova ${ }^{2}$, and L.I. Abbasova ${ }^{3}$ \\ ${ }^{1}$ V.I. Vernadsky Crimean Federal University, Simferopol, Russia \\ ${ }^{2}$ State Educational Institution of Higher Education of the Moscow Region Moscow Region State \\ University, Mytishchi, Russia \\ ${ }^{3}$ State Budget Educational Institution of Higher Education of the Republic of Crimea Crimean \\ Engineering and Pedagogical University the name of Fevzi Yakubov, Simferopol, Russia
}

\begin{abstract}
The article discusses issues related to the study of the main attributes of the modern digital media space - social networks. The key issue, which is reflected in this article, concerns the educational potential of social networks, as well as their abilities in the context of the system of professional training of modern, competitive and most relevant specialists. The essence and specificity of social networks, their segments, effects and developing areas are determined. The possibilities of using social networks in the modern educational process in universities are revealed, and the process of their use is actualized, their certain potential is emphasized, as well as the effectiveness and inefficiency of individual elements of social networks. The study was based on a questionnaire survey - one of the most statistically useful and significant methods for researching the impact and effectiveness of socially significant technologies used in any area. The questioning was carried out among the student and pedagogical communities of the Republic of Crimea through a questionnaire and a survey posted on the "Vkontakte" social network, receiving the priority attention of most students and teachers both for personal communication and for remote interaction for educational purposes. In total about 100 teachers and about 150 students from various Crimean universities, areas of training, forms of education took part in the survey. The topic of the questionnaire is "The determination of educational opportunities for using social networks in the modern educational space of the university" and "The identification of the most effective options for using social networks in the modern educational process of the university". The respondents gave answers to the questionnaire questions anonymously and impartially, which guarantees the reliability and accuracy of the results obtained.
\end{abstract}

\section{A problem statement}

The sphere of education has always been considered to be one of the highest priorities in terms of development and equipment, since it represents an important layer of modern

*Corresponding author: ipcs-profped@yandex.ru 
society. Education today is not just an opportunity for students to get a specialty and become professionals in their field, but also to expand the capabilities of each of the students, to form the main social potential of the state, and to create a stable platform for the development of its economy. As a result of this it is fair to talk about the regular equipping of this sphere with all kinds of optimizing technologies, which inevitably relate to the field of remote social and socio-cultural interaction of the subjects of society. Today the active use of digital and other distance technologies, their individual elements, in our case, social networks in educational practice has become one of the important tools of such equipment. Social networks take special place in the life of every modern person, affect all spheres of his life and significantly expand the range of his capabilities both in social and in creative, educational, professional areas. It is on this that the research problems are based: the use of social networks in education is often practiced today, but remains a fairly new phenomenon that does not inspire confidence among the majority of university teachers. Traditional education presupposes direct interaction between a teacher and a student in the format of live communication; social networks deprive this aspect of educational activity. In this regard, a number of problems and problematic questions arise: how effective are social networks and their components in the educational process? What are the opportunities and potential of using social media in education? How is it possible to optimize the educational process and the process of direct professional training of modern specialists? All these issues form the basis of the problems of this study and require significant attention from native and foreign scientists, teachers, sociologists, etc. In our opinion, focusing on this kind of problematic aspects of education, it is possible to get as close as possible to solving the issue of intensifying and modernizing of higher education in the country.

\subsection{The objective of the work}

The problem of this study did not arise now, but at the time of the appearance of the first social networks and at the time of their active spread. In this regard, modern native pedagogical science has been replenished with a number of scientific works related to the disclosure of the problems of educational opportunities of social networks. In our opinion the key studies were the works of such authors as O.M. Abramova, O.A. Solovyova, T.L. Arkhipova, N.V. Osipova, M.S. Lvov, I.I. Aslanov, D.A. Talybova, L.G. Bekhtereva, N.Yu. Margolis, V.A. Nikitenko, I.N. Golitsyn, M.D. Goryachev, N.V. Ivanushkina, V.V. Mantulenko, M.A. Dyachkova, O.N. Tomyuk, A.V. Lyamin, A.R. Hobotova, M.S. Chezhin and others.

It was these scientific articles that formed the basis of the theoretical substantiation of this work, and also represented an important theoretical potential for the development of the topic. All of them are equipped with an intense pedagogical scientific apparatus, in connection with which it would be fair to note that this is why, analyzing and comparing the judgments presented in them, we are able to form our own system of disclosing of this topic, to conduct a competent and most socially significant and complete questionnaire, etc.

The introduced study aims to replenish the theoretical and practical basis in relation to searching ways of solving the above-mentioned pedagogical problems, and also presents its own individual view of them.

\section{Materials and the results of the research}

The goal setting of this study is based on the key aim pursued by the authors - an objective identification of the role and place of social networks in the modern system of higher education, as well as the identification of key opportunities for using them in the modern 
system of professional training of future specialists in various fields of training, forms and degrees of education. The achieving of such a goal is possible only by performing a number of tasks, consisting of the following:

- defining the role of social networks in the system of socio-cultural exchange of knowledge within the whole society;

- identification of the most effective technologies and elements of social networks for the educational process;

- conducting a comprehensive analytical study and comparison with the experience of leading educational specialist who are faced with the phenomenon of social networks and their impact on education;

- comparison of the views of two educational groups - teachers and students regarding the effectiveness of various options for using social networks in the educational process;

- considering the advantages and disadvantages of using social media in education.

The solution of the above-mentioned tasks will allow us to achieve the main goal of the study and to put it in a number of pedagogically significant works, as well as to actualize the problems of using social networks in education. This will allow the formation of a scientific potential, which will be further revealed by other researchers. In addition, on the basis of this study it is possible to conduct other, more extensive and global studies and scientific searches for a solution to the problem.

Education at the present stage is largely characterized by the active and intensive inculcation of information and communication technologies into its structure, capable of influencing not only the essence of educational activity, but also the teaching methodology. Such technologies pursue the goal of developing and intensifying education, intellectual and creative abilities of students, improving the quality of educational services provided by modern educational institutions $[3 ; 11 ; 17]$.

The sphere of socio-cultural interaction of modern people is quite extensive and includes many means that allow them to maintain communication at various stages, territorial and time intervals. It is with this that the active use of social networks is associated, which allows not only to transmit the necessary information quickly and accurately, but also to exchange educational resources, to intensify the process of interaction between the teacher and students. However, it would be wrong to believe that the emergence of such networks can completely solve the problems of time and space costs, information transfer rate, etc. In our opinion, such technologies should not be idealized, since their application in teaching also has a lot of disadvantages, along with obvious advantages. Like any element of distance learning, social networks underlie the formation of the latest pedagogical objectives, problems and crises, and are also important means of forming new educational standards [8]. All this entails the constant development of qualitatively new forms, means and methods of teaching, which are not always able to fully satisfy the needs of both teachers and students. At the same time, we must not forget about the social significance of such an implementation - personal communication is becoming as "outlandish" as social networks and remote communication services were at one time. In this regard it seems to us especially important to consider the various positions that exist today concerning the variants of using social networks, their potential in education, as well as the positive and negative aspects of such use [3].

Social networks are special online platforms used by people to establish interpersonal communications and the implementation of direct interaction and social relations with other people [4]. A.V. Feschenko, in this regard, believes that "the space of social networks today is very actively mastered by students of different ages. However, their main purpose is primarily entertainment" [18]. In this regard, in order to transform the digital space already familiar to modern people into an educational environment that has all the capabilities and 
means to equip the process of self-education, a teacher is required. It is him, who is a key link in the educational chain that carries out organizational, administrative and sociopsychological manipulations to equip the educational environment with useful tools [2].

The use of such online platforms in education, as noted by O.M. Abramova and O.A. Solovyov, "may be directly related to the management of the educational process" [1]. Here the teacher is responsible for a range of tasks, which are to find and to arrange theoretical materials for students correctly. Moreover, it should be arranged in the most relevant and entertaining form - multimedia. It is important not only to provide theoretical material, but also to equip it with an interesting form and specificity for students, reinforcing it with practical work and exercises [5].

Besides, social networks provide users with extensive opportunities for storing information in a convenient form, as well as with transmitting it as quickly and comprehensively as possible. Thanks to this, every year an increasing number of information databases are created, which serve as a significant assistance to modern students in the process of obtaining qualifications or educational knowledge. The creation of such databases directly by students is often accompanied by various visual materials that activate and intensify the process of acquiring knowledge, and also allow them to show creative abilities in the most comfortable form for modern users [7]. Creativity plays a key role here, since the student, who compiles his database necessary for him in learning, aspires to equip it with the most interesting visual, auditory and multimedia additions that focus not only on evidence, but also on the problems and potential of that or another area of knowledge. Moreover, such creativity significantly activates the motivational aspects of cognitive activity and contributes to the maximum involvement of the student in the process of obtaining professional competence [9].

Many researchers [13] identify a whole range of positive and negative aspects of using social networks in the modern educational process. In our opinion, such an analysis is important for this study, as it is an area from which one can draw certain conclusions and initial inferences necessary for conducting a questionnaire. Besides, the identification of such aspects deepens us further in the study of the specifics of this topic.

In modern native pedagogical science, it is customary to single out the following positive aspects of using social networks in the modern educational process in universities:

- orientation towards students, which manifests itself in the adaptation of social, entertainment and communication online platforms familiar to all students to educational activities;

- a convenient and full-fledged set of tools that allow you to exchange, store and edit educational information;

- a significant reduction in the cost of distance education: today the material and technical base of the university is one of the most problematic elements of the education system, since it is quite expensive, while access to social networks does not require special equipment - it is achieved through a smartphone, which every student and teacher have today;

- activation of communication processes, development of the communicative potential of students, the rapid formation of communicative culture;

- increasing and deepening of communication experience of teachers who are in constant interaction with students and other subjects of the educational process;

- support of the continuous education system;

- wide access of students and teachers to the information they need: educational information remains open for all the subjects of the educational process all the time, to obtain it you need only the access to the Internet;

- a significant increase in the time spent on training, as well as the capacity of training, since online platforms allow conducting classes outside the classroom time, which activates 
the mental activity of students and makes them work harder and better $[9 ; 10 ; 13 ; 14 ; 16$; 17].

The disadvantages of using social networks in the modern educational process include the following aspects:

- the complexity of the organizational and administrative pedagogical equipment of the educational process;

- the presence of additional information of an entertaining nature in social networks, which is not related to educational activities and can significantly complicate the process of students' perception of information;

- the need for technical means for subjects of the educational process in the form of a computer, laptop or smartphone, etc.;

- the low level of self-organization and poor skills of rational distribution of working and free time among students;

- the complexity of the assessment and control of students' activities by the teacher [15; 16].

Having considered the advantages and disadvantages, we can point to the fact that all of them can flow into each other and become mutually complementary in the case of improper and irrational usage of social networking technology in education. It is important to understand that it is possible to eliminate drawbacks only if all the subjects of the educational space apply the maximum of opportunities [11].

The next stage of this research was to conduct a questionnaire based on the analysis of pedagogical scientific literature in the field of organizing distance learning. This analysis allowed us to highlight the key possibilities of using social networks in the modern educational process, which are described and discussed below. It seems to us the most logical to compare the results of the survey with the existing capabilities of social networks for the most comprehensive deepening into the topic. Moreover, let us note that the questionnaire is the result of a study of both the pedagogical and student communities, which will allow us to draw an extensive and objective conclusion. Below we will consider all the possibilities of using social networks in education and compare them with the results of the survey, which are presented in tables 1 and 2 .

Table 1. The degree of students' satisfaction with the quality of educational services provided in the context of the active use of social networks in the organization of the educational process (\%).

\begin{tabular}{|l|l|l|l|l|}
\hline & $\begin{array}{l}\text { Absolute } \\
\text { satisfaction }\end{array}$ & $\begin{array}{l}\text { Partial } \\
\text { satisfaction }\end{array}$ & $\begin{array}{l}\text { Partial } \\
\text { dissatisfaction }\end{array}$ & $\begin{array}{l}\text { Absolute } \\
\text { dissatisfaction }\end{array}$ \\
\hline $\begin{array}{l}\text { The quality of } \\
\text { individual, team and } \\
\text { group work }\end{array}$ & $\mathbf{4 9 , 4}$ & 22,2 & 14,7 & 13,7 \\
\hline $\begin{array}{l}\text { The quality of the } \\
\text { organization of } \\
\text { educational activities }\end{array}$ & 28,6 & 18,8 & $\mathbf{3 6 , 7}$ & 16,1 \\
\hline $\begin{array}{l}\text { The quality of } \\
\text { organization of } \\
\text { extracurricular activities }\end{array}$ & $\mathbf{3 4 , 4}$ & 28,8 & 25,2 & 11,6 \\
\hline $\begin{array}{l}\text { The quality of project } \\
\text { activities }\end{array}$ & $\mathbf{6 0 , 5}$ & 14,9 & 13,2 & 11,4 \\
\hline $\begin{array}{l}\text { The quality of resource } \\
\text { and information sharing }\end{array}$ & $\mathbf{4 1 , 8}$ & 22,5 & 13,4 & 22,3 \\
\hline $\begin{array}{l}\text { The quality of self- } \\
\text { education of students }\end{array}$ & $\mathbf{6 3 , 5}$ & 14,7 & 3,6 & 18,2 \\
\hline $\begin{array}{l}\text { The quality of self- } \\
\text { education of teachers }\end{array}$ & 7,4 & 14 & $\mathbf{4 1 , 9}$ & 36,7 \\
\hline
\end{tabular}


Table 2. The degree of teachers' satisfaction with the quality of educational services provided in the context of the active use of social networks in the organization of the educational process (\%).

\begin{tabular}{|c|c|c|c|c|}
\hline & $\begin{array}{l}\text { Absolute } \\
\text { satisfaction }\end{array}$ & $\begin{array}{l}\text { Partial } \\
\text { satisfaction }\end{array}$ & $\begin{array}{l}\text { Partial } \\
\text { dissatisfaction }\end{array}$ & $\begin{array}{l}\text { Absolute } \\
\text { dissatisfaction }\end{array}$ \\
\hline $\begin{array}{l}\text { The quality of } \\
\text { individual, team and } \\
\text { group work }\end{array}$ & 16,6 & 29,7 & 12,4 & 41,3 \\
\hline $\begin{array}{l}\text { The quality of the } \\
\text { organization of } \\
\text { educational activities }\end{array}$ & 18,9 & 24,1 & 37,3 & 19,7 \\
\hline $\begin{array}{l}\text { The quality of } \\
\text { organization of } \\
\text { extracurricular activities }\end{array}$ & 51,2 & 24,2 & 17,8 & 6,8 \\
\hline $\begin{array}{l}\text { The quality of project } \\
\text { activities }\end{array}$ & 42,5 & 26,4 & 11,8 & 19,3 \\
\hline $\begin{array}{l}\text { The quality of resource } \\
\text { and information sharing }\end{array}$ & 48,6 & 14,5 & 26,5 & 10,4 \\
\hline $\begin{array}{l}\text { The quality of self- } \\
\text { education of students }\end{array}$ & 15,3 & 17,2 & 23,4 & 44,1 \\
\hline $\begin{array}{l}\text { The quality of self- } \\
\text { education of teachers }\end{array}$ & 20,4 & 30,1 & 21,4 & 28,1 \\
\hline
\end{tabular}

The possibility of organizing individual, collective and group work is one of the most significant in the system of organizational and administrative potential of social networks in education. $71.6 \%$ of the students considered that in the Crimean universities such an opportunity is satisfactory and implemented at a sufficiently high level. At the same time, $53.7 \%$ of teachers consider it exactly the opposite. It is important to understand that a harmonious combination of individual and group activities significantly affects the mastering and understanding of educational material [7]. Social networks are the best suited for such an organization, but much still depends on the degree of self-organization of students, which, according to teachers, is quite low. Students are distracted by extraneous messages, while teachers do their best to avoid this - hence there is the contradiction between these other communities.

The quality of the organization of educational activities in native realities through social networks was recognized as extremely unsatisfactory by both students and teachers $52.8 \%$ of students and $57 \%$ of teachers expressed dissatisfaction with the organizational structure of social networks. It is important to understand that educational activities by means of such technologies require significant experience from teachers in the field of organizing distance learning [2]. Native teachers are in many ways quite far from Western ones, who have long been working in tandem with modern technologies. This raises the problem of organizing educational activities.

Extracurricular activities organized within the framework of social networks were recognized as of higher quality, which is proved by the percentage ratio of respondents' satisfaction $-63.2 \%$ on the part of students and $75.4 \%$ on the part of teachers, respectively. Extracurricular activities conclude mainly with the holding of Olympiads, competitions, media conferences, presentations, etc. Social networks provide all kinds of resources for the implementation of these activities and are the most open platforms for this [4]. In this case, since all this relates more to educational creativity than to the theoretical mastering of educational material, students are more interested and motivated to implement their activities in the context of social networks, and therefore their effectiveness increases. Teachers note that extracurricular activities are as important as educational activities, which is also extremely important in the education system using social networks [15]. 
One of the most satisfactory variants for using social networks in education is the organization of project activities of students. This is confirmed by statistical data $-75.4 \%$ of positive assessments from students and $68.9 \%$ from teachers. The variant of using social networks for their intended purpose was overtaken by the same fate - for exchanging resources and information $-64.3 \%$ of students' satisfaction and $63.1 \%$ of teachers.

The most interesting for us was the analysis of the last two rows of the table given above. The fact is that students $(78.2 \%)$ considered that the possibility of the influence of social networks on their self-education is extremely high, but the same influence on teachers was rated low $-78.6 \%$. Teachers, on the other hand, believe that the opposite is true, that the possibility of self-education through social networks is, in principle, impossible. This is due to the predominant filling of social networks with entertainment content. Teachers with significant experience in professional activities agree that entertainment content is the main enemy of productive educational activity, and services for learning should be narrowly focused and specialized.

In general, in conclusion, we would like to cite the authoritative opinion of O.A. Klimenko, with whom we are fully in solidarity: "social networks provide wide opportunities for maintaining relations between all subjects of educational relationships" [10].

\section{Conclusions}

Based on the results of the above study, we can conclude that the use of social networks in the modern educational process is a rather arguable and controversial step that can stimulate the development of both positive and negative processes taking place in the modern system of higher professional education. However, with correct and harmonious implementation, it is possible to expand the digital space of an educational institution, to stimulate students to deep into the educational process, and to form a fundamentally new digital culture of thinking of new generation specialists.

\section{References}

1. O.M. Abramova, O.A. Solovieva, The use of social networks in the educational process, Young scientist, 9 (2016)

2. T.L. Arkhipova, N.V. Osipova, M.S. Lvov, Social networks as a means of organizing the educational process, Information technologies in education, 22 (2015)

3. I.I. Aslanov, D.A. Talibova, Virtual social networks in the education system of the information society, Bulletin of Science and Education, 9 (2015)

4. L.G. Bekhtereva, N.Yu. Margolis, V.A. Nikitenko, Possibilities of using social networks in the modern educational process in universities, Young scientist, 6 (2015)

5. I.N. Golitsyna, Social networks as a virtual educational space, School technologies, 4 (2013)

6. M.D. Goryachev, N.V. Ivanushkina, V.V. Mantulenko, Application of network resources in modern education, Bulletin of SamSU, 5 (2014)

7. M.A. Dyachkova, O.N. Tomyuk, Social networks as an educational resource, Pedagogical education in Russia, 17 (2014)

8. S.A. Zolotukhin, The role of social networks in the informatization of education, Discussion, 5 (2013) 
9. I.V. Zorina, Social services, networks and communities in education, Scientific research in education, 8 (2008)

10. O.A. Klimenko, Social networks as a means of teaching and interaction of participants in the educational process, Theory and practice of education in the modern world, 405-407 (2017)

11. S.A. Livshits, Practices of using social networks in higher education, 17 (2014)

12. V.Yu. Lyskova, K.S. Weber, Social networks: application in education, formation of the university's image, 2 (2014)

13. A.V. Lyamin, A.R. Hobotova, M.S. Chezhin, The use of social networks in education, $67(2015)$

14. V.A. Matanis, Social networks in education: designing mass information flows, Actual problems of the humanities and natural sciences, 6 (2015)

15. G.B. Sayfutdinova, N.V. Danilova, Social media in higher education. practice of application, Actual problems of the humanities and natural sciences, 2 (2017)

16. G.B. Sayfutdinova, M.A. Khramtsova, Possibilities of the Internet and social networks in the system of higher education, Actual problems of the humanities and natural sciences, 11 (2015)

17. I.S. Tkachenko, Yu.I. Bogatyreva, Using the possibilities of social networks in the educational process, Scientific result, Pedagogy and psychology of education, 3 (2017)

18. A.V. Feschenko, Social networks in education: analysis of experience and development prospects, Open and distance education, 3 (2011) 